\title{
The effects of natural and mixed convection on heat transfer across adjacent micro-channels, in extreme pressure and temperature conditions
}

DOI:

10.1016/j.applthermaleng.2016.06.052

\section{Document Version}

Accepted author manuscript

Link to publication record in Manchester Research Explorer

Citation for published version (APA):

Cooper, D., Cotton, M., lacovides, H., \& Zhang, S. (2016). The effects of natural and mixed convection on heat transfer across adjacent micro-channels, in extreme pressure and temperature conditions. Applied Thermal Engineering, 106. https://doi.org/10.1016/j.applthermaleng.2016.06.052

Published in:

Applied Thermal Engineering

\section{Citing this paper}

Please note that where the full-text provided on Manchester Research Explorer is the Author Accepted Manuscript or Proof version this may differ from the final Published version. If citing, it is advised that you check and use the publisher's definitive version.

\section{General rights}

Copyright and moral rights for the publications made accessible in the Research Explorer are retained by the authors and/or other copyright owners and it is a condition of accessing publications that users recognise and abide by the legal requirements associated with these rights.

\section{Takedown policy}

If you believe that this document breaches copyright please refer to the University of Manchester's Takedown Procedures [http://man.ac.uk/04Y6Bo] or contact uml.scholarlycommunications@manchester.ac.uk providing relevant details, so we can investigate your claim.

\section{OPEN ACCESS}


The effects of natural and mixed convection on heat transfer across adjacent micro-channels, in extreme pressure and temperature conditions

Dennis Cooper, Mark A. Cotton, Hector Iacovides and Shanying Zhang

Turbulence Mechanics Group, School of Mechanical, Aerospace and Civil Engineering. The University of Manchester, Manchester M13 9PL, U.K.

h.iacovides@manchester.ac.uk

\begin{abstract}
This abstract summarizes a mainly experimental investigation of heat transfer across an insulation pack specimen used to protect the upper surface of the Hot Box Dome of an advanced gas cooled nuclear reactor from the hot gas above it, under actual operating conditions. The pack consists of multiple stainless steel layers forming narrow channels, less than $1 \mathrm{~mm}$ wide between them. The facility developed, can operate at pressures of $40 \mathrm{bar}$, temperature differences across the insulation pack of up to $500{ }^{\circ} \mathrm{C}$, with and without flow through the pack channels and at horizontal and inclined orientations. Measurements led to the calculation of the effective thermal conductivity and also the mapping of the temperature variation across the pack for a range of flow rates, and also for angles to the horizontal of up to $30^{\circ}$. The effective conductivity data show how, under these extreme pressure and temperature conditions, the rate at which thermal energy is transferred to the lower cold side of this multi-channel pack, depends on the Rayleigh and Reynolds numbers at different angles of inclination. The corresponding local temperature measurements advance understanding of the local thermal characteristics and suggest the presence of strong flow structures. The most striking finding is the strong influence of buoyancy for all flow rates investigated, even for the horizontal cases. Tests at inclined orientations suggest the presence of flow reversal. Complementary conjugate heat transfer numerical analysis, using a simplified two-dimensional representation of the pack has also been carried out. For the inclined case the flow computed features are consistent with those suggested by the local temperature data.
\end{abstract}

\title{
1. Introduction
}

This experimental investigation considers conjugate heat transfer that takes place across insulation packs, which consist of a set of multiple parallel micro channels formed between adjacent metallic foils, when exposed to extreme pressures, and with a high temperature difference across them. The motivation arises from the fact that such packs are used in advanced gas cooled nuclear reactors (AGR) to protect the Hot Box Dome which, as shown in Figure 1, is used to separate the hot gas that emerges from the fuel cooling passages from the cooler gas in the region around the core. The primary objective of these experiments has been, through measurements of the temperature difference across the pack and of the thermal energy supplied to it, to determine its thermal conductivity at a horizontal orientation which would correspond to the location at the center of the dome and also with the pack inclined to the horizontal at angles of up to $30^{\circ}$, which covers the full range of off-center locations, and also for a range of flows of hot gas through the pack. The latter will correspond to the reactor gas which leaks into the narrow inter-layer passages and is driven from the center of the dome outwards. A further objective of this research has been, through temperature measurements across the pack, to try and understand the flow and thermal developments under the different operating conditions. Numerical simulations of a simplified two-dimensional version of the insulation specimen have also been produced to help with the second objective. Depending on 
the combination of angle of inclination and through-flow, the dominant mode of heat transfer across the micro-channels is consequently expected to vary from heat conduction to natural, mixed and possibly forced convection.

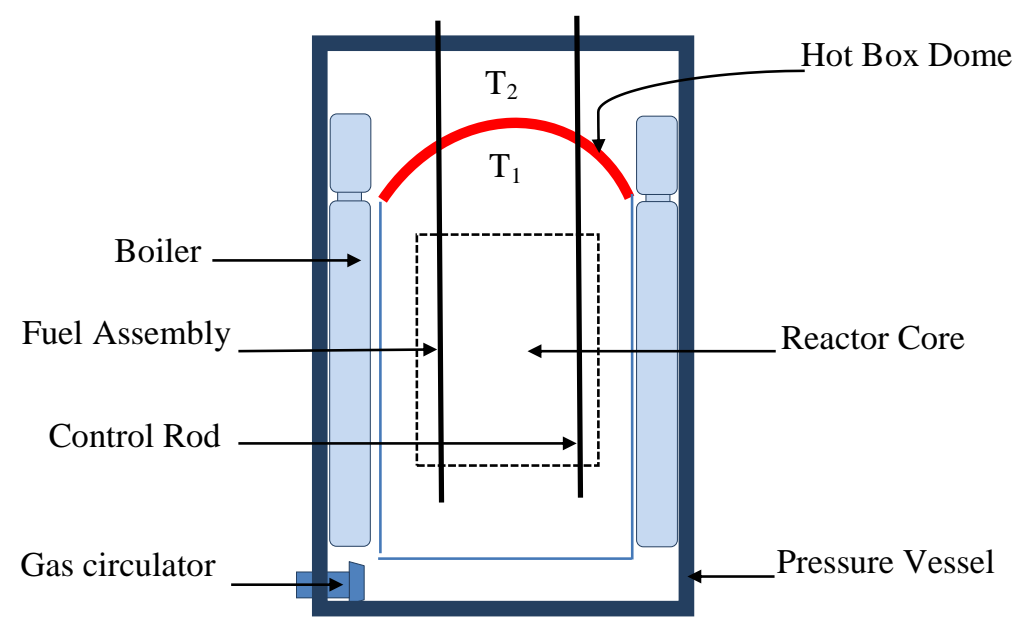

Figure 1. Schematic diagram of an Advanced Gas Cooled Reactor

In consequence of the novelty of the experimental investigation to be reported here, there appears to be little in the literature, in terms of fundamental studies, with direct bearing on the present subject matter. Nonetheless, there are studies of related, but simpler, geometries, namely flows over isolated heated flat plates, and convective heat transfer in channels and cavities. We therefore take a look at such flows with the aim of identifying physical phenomena that bear some relation to the features found in the multiple-plate reactor insulation and which are to be discussed later in the paper. Here horizontal and inclined flows are considered. The focus is on laminar flow and on studies with thermal boundary conditions akin to those imposed here, i.e. 'stable' situations where flows are heated from above or cooled from below. Where such works exist, there is an emphasis on experimental studies. As original sources are cited, it will become clear that parts of the present literature review are of a somewhat historical nature, this being a direct consequence of the period during which a number of pioneering studies were undertaken (although efforts have been made to access the most recent editions of secondary sources). The final part of the review examines the extremely limited body of work with a more immediate connection to the present investigation.

Of all the flow and heat transfer situations to be considered here, free convection over an isolated horizontal flat plate is the most completely documented. Much of the canon of experimental work on the subject is collected in classical heat transfer textbooks. A good example is Holman [1] who includes a chapter on natural convection, paying particular attention to the empirical correlations advanced by various investigators. Incropera et al. [2] adopt a similar approach. Other textbooks include that by Bejan[3] which provides a good coverage of scaling analysis, although the focus is upon vertical external flows where the boundary layer approximations are applicable, while similarity solutions form the principal subject matter of Cebeci[4]. Jaluria[5] gives a more specialized treatment which concentrates on natural convection.

As noted above, current interest relates to the stable horizontal plate configuration. An early 
correlation for laminar free convection air flow over downward-facing heated square and rectangular plates was advanced by Fishenden and Saunders [6]:

$$
\mathrm{Nu}{ }_{\delta}=\mathrm{C}\left(\mathrm{Gr}{ }_{\delta} \mathrm{Pr}\right)^{n}
$$

where $C=0.25$ and $n=0.25$. McAdams [7] subsequently revised the value of $C$ to 0.27 .

$$
N u_{\delta}=\frac{h_{\delta} \delta}{k} ; \quad G r_{\delta}=\frac{\beta g\left(T_{H}-T_{C}\right) \delta^{3}}{v^{2}}
$$

Here $T_{C}$ corresponds to the free-stream temperature (frequently denoted ' $T_{\infty}$ '). The product $G r_{\delta} P r$ is also known as the Rayleigh number, $R a_{\delta}$. Eq. (1) is valid for $3 \times 10^{5} \leq R a_{\delta} \leq 3 \times 10^{10}$. Fishenden and Saunders specified the characteristic length scale, $\delta$, as either the side of a square test specimen or, in the case of a rectangular specimen, the average side length. In a refinement of this formulation, Goldstein et al. [8] proposed that $\delta$ for a rectangular plate or other horizontal surface should be evaluated as the ratio of $A$, the surface area to the perimeter, $P$. In the present work, however, because only two of the four sides of the insulation pack layers are open to the flow, it seems appropriate to replace $P$ by $2 L$, where $L$ is the side length of the square test specimen (hence $\delta=L / 2$; in subsequent comparisons made with Eq. (1) ).

Turning next to imposed flow over a heated plate, the thermal-hydraulic regime becomes one of 'mixed', or combined forced and free convection (assuming that conditions are not such that a wholly forced convection regime obtains). Lin et al. [9] provide a summary of analytical and numerical works on the subject. In a rare experimental study, Wang [10] reported results for air flows over both upward- and downward-facing horizontal heated plates in the free, mixed, and forced convection regimes. In both orientations there are two asymptotes: one where the Nusselt number becomes a function of Grashof number only (in the free convection, relatively low Reynolds number regime), and the other where the Nusselt number depends only on the Reynolds number (in the forced convection, or relatively low Grashof number regime). In particular at high Grashof numbers the local Nusselt number-Grashof number relationship is found to have the same exponents as those in pure free convection ( $n=1 / 4$ for laminar downward-facing case, cf. Eq. (1), and $n=1 / 3$ for turbulent upward-facing). In the upward-facing case the local Nusselt number at a given Grashof number and increasing Reynolds number asymptotes fairly smoothly through the mixed convection regime, to join the pure forced convection limit. For the heated downward-facing plate, heat transfer levels can be impaired with Nusselt numbers in the mixed convection regime exhibiting a significant 'dip' below forced convection values.

Experimental studies of inclined flat plate free convection heat transfer have tended to characterize the regime in terms of plate inclination to the vertical. Fujii and Imura [11] used water as the working fluid and conducted experiments on both downward- and upward-facing heated plates. The thermal boundary condition was between uniform wall heat flux and uniform wall temperature. Heat transfer correlations are presented in terms of Grashof number, Eq (2), with $T_{H}$ evaluated at the plate mid-height. In the downward-facing case the Nusselt number could be correlated as

$$
N u_{\delta}=0.56\left(R a_{\delta} \cos \theta\right)^{0.25}
$$


where $\theta$ is the plate angle to the horizontal. The expression is valid for $10^{5} \leq R a_{\delta} \leq 3 \times 10^{11}$ and $\theta \leq 87^{\circ}$. (It is noted that the coefficient for a vertical plate with uniform wall temperature is more generally taken as 0.59, see for example McAdams [7] and Holman [1].) The replacement of Rayleigh number in vertical plate free convection correlations by an expression of the form $R a \cos \theta$ was first proposed by Rich [12]. The modification proves to be highly satisfactory where a heated plates faces downward, but not in the upward-facing orientation [11].The inability of the sine/cosine adjustment to account for heat transfer in the upward-facing case is associated with the three-dimensionality of the flow in the form of longitudinal vortices [13].

For channel flows, Azevedo and Sparrow [14] reported an experimental investigation of laminar natural convection of water flow in inclined channels. One or both walls could be heated and the walls were isothermal in all tests. When the upper wall was heated and the lower wall unheated ('stable' configuration), average Nusselt numbers were extremely well correlated by Eq. (4):

$$
N u_{L}=0.644\left[(L / H) R a_{L} \sin \theta\right]^{0.25}
$$

By contrast, where the lower wall was heated (the 'unstable' case) with an inclination angle $\theta=45^{\circ}$, there arose significant departures from Eq. (4), Nusselt numbers exceeding the values indicated by the correlation. Azevedo and Sparrow also used a flow visualization technique to reveal, for upper wall heated cases, the existence of a re-circulating flow towards the upper region of the unheated (lower) wall. Interestingly, however, such pockets of recirculation do not cause the Nusselt numbers to depart from Eq. (4).

Differentially-heated cavity flows were studied experimentally by Cooper et al.[15]. Natural convection in a differentially heated air-filled $(P r \approx 0.71)$ rectangular cavity with longitudinal and lateral aspect ratios of 28.6 and 6 respectively was investigated. Results were reported for inclinations to the horizontal of $\theta=15^{\circ}$ and $60^{\circ}$, with both upper wall and lower wall heated configurations. In the $60^{\circ}$ cases studied the natural circulation flow remained two-dimensional. At the lower $15^{\circ}$ angle of inclination, the flow became three-dimensional, both for the case where the lower wall and the one where the upper one was heated. The latter result for the stable configuration was unexpected. In both cases longitudinal vortices were detected, accompanied by rotating cells in the cross-sectional plane parallel to the thermally active sides. A subsequent numerical investigation by Ammour et al [16] confirmed the presence of longitudinal vortices at the $15^{\circ}$ angle.

No fundamental experimental research on mixed convection in channels heated from above has been located. When it comes to more industrially focused research, the most relevant publication Axcell et al [17], has originated from the authors' group in Manchester and reports attempts to investigate heat transfer across the hot box dome insulation packs of the earlier, Magnox, design of gas-cooled nuclear reactors. In that earlier attempt, however, the pressure range was limited to 5 bar (instead of 40 bar in the current study), the maximum temperature was below $400{ }^{\circ} \mathrm{C}$, and no attempt was made to map the local temperature field across the insulation pack. Consequently only global information was produced over a limited range of operating parameters. Nevertheless the Axcell et al [17] study provided some indication that increases in pressure and temperature differences do result in an increase in the effective thermal conductivity of the insulation pack. 
This brief review of the literature shows that there are no detailed studies of conjugate heat transfer across multiple parallel channels separated by metallic layers, under stable thermal stratification, for the pressure and temperature differences encountered in gas cooled nuclear power plants. Detailed experimental data either for simpler cases, or less detailed data at considerably lower pressures (and consequently Rayleigh numbers) provide some guidance of the likely effects of mixed and natural convection and also of the angle of inclination on heat transfer. In this experimental study we try to answer what happens to global parameters, like the effective thermal conductivity, under more extreme operating conditions, and what are the effects on the local thermal (and by implication flow) field which explain the global trends.

\section{Experimental Setup}

As can be seen in Figure 2, the type of insulation considered consists of multiple square stainless steel layers. Each of the layers has a ratio of thickness-to-length of 0.0051 and consists of two plane sheets with a corrugated foil (not shown here) separating them. The first 4 , dome-adjacent, layers are stacked flush upon one another, while the remaining layers are separated by narrow gaps, with a gap-to-length ratios of 0.0015 . The first 18 of the foils, from the bottom up, have welded ends, while the top 9 are left open. This is done so that the reactor gas, which leaks into the narrow inter-layer passages and is driven from the center of the dome outwards, flows predominantly through the open topmost layers, which offer lower flow resistance than the other layers. The rationale for this is that if the flow within the pack is diverted away from the surface of the dome, heat transfer to it will be reduced. The ratio of the total thickness of the insulation pack, $H$, to its length, $L$, is 0.185 . The operating gas (carbon dioxide) pressure is $40 \mathrm{bar}$. The gas temperature above the dome $\left(T_{2}\right.$ in Figure 1$)$, is around $600{ }^{\circ} \mathrm{C}$, while below it $\left(T_{1}\right)$ the temperature is at around $200{ }^{\circ} \mathrm{C}$.

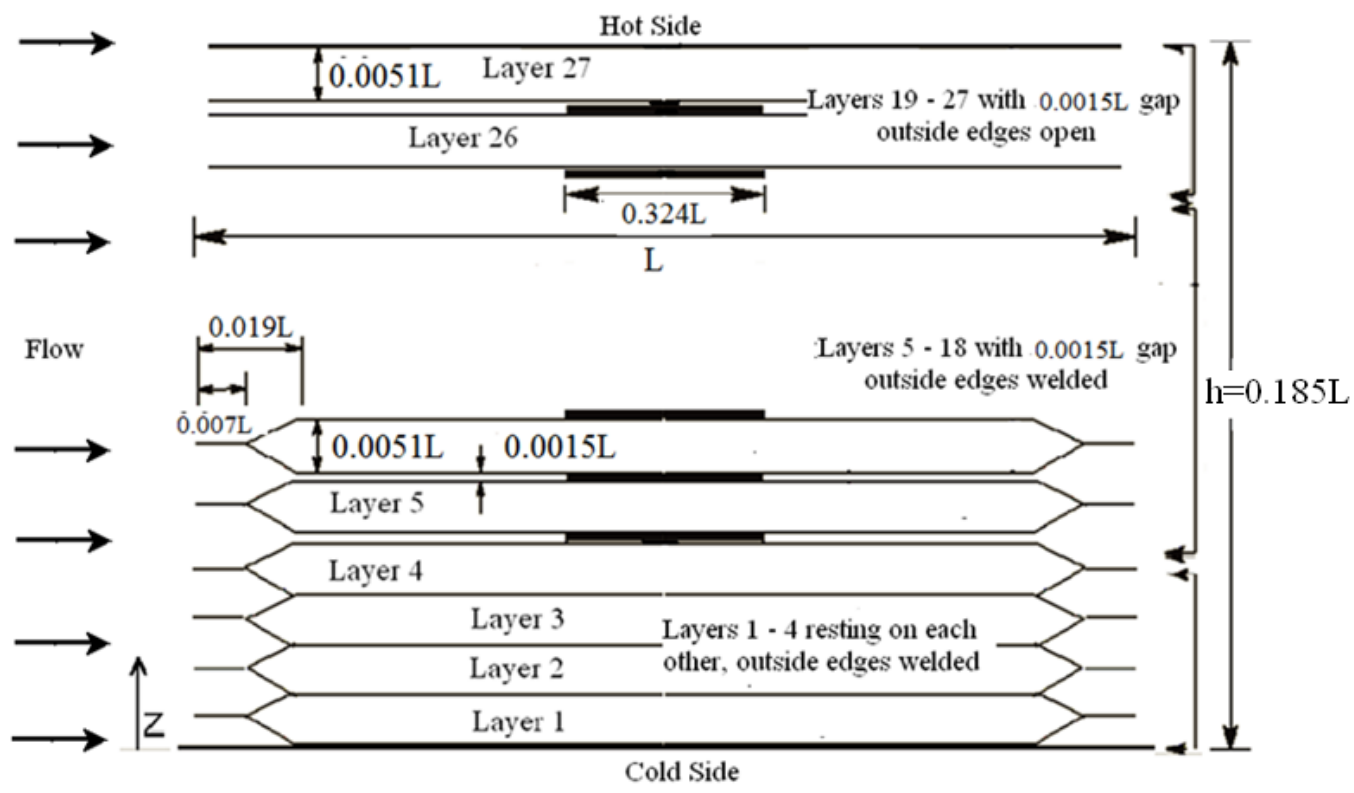

Figure 2. Side-view of the above dome insulation pack used in the experimental study. Not to scale 
The experimental set up is presented in the schematic diagram of Figure 3. A booster compressor raises the pressure of the air received from the laboratory's compressed air supply from 15 to 40 bar. The compressed air is then stored in a receiver tank, to ensure stability and then passes through a dryer to remove moisture. The air then flows through an orifice plate section constructed according to the international standards EN ISO 5167-2-2003, to monitor the mass flow rate. Before entering the pressure vessel, the air passes through an external heating section, which, if needed, can increase the temperature of the air before it enters the insulation pack. As also shown in Figure 3, in addition to the compressed air circulation system, there is also a cooling water system, which circulates water, at a pressure of 3 bar through the pressure chamber, in order to maintain the necessary temperature difference across the insulation pack.

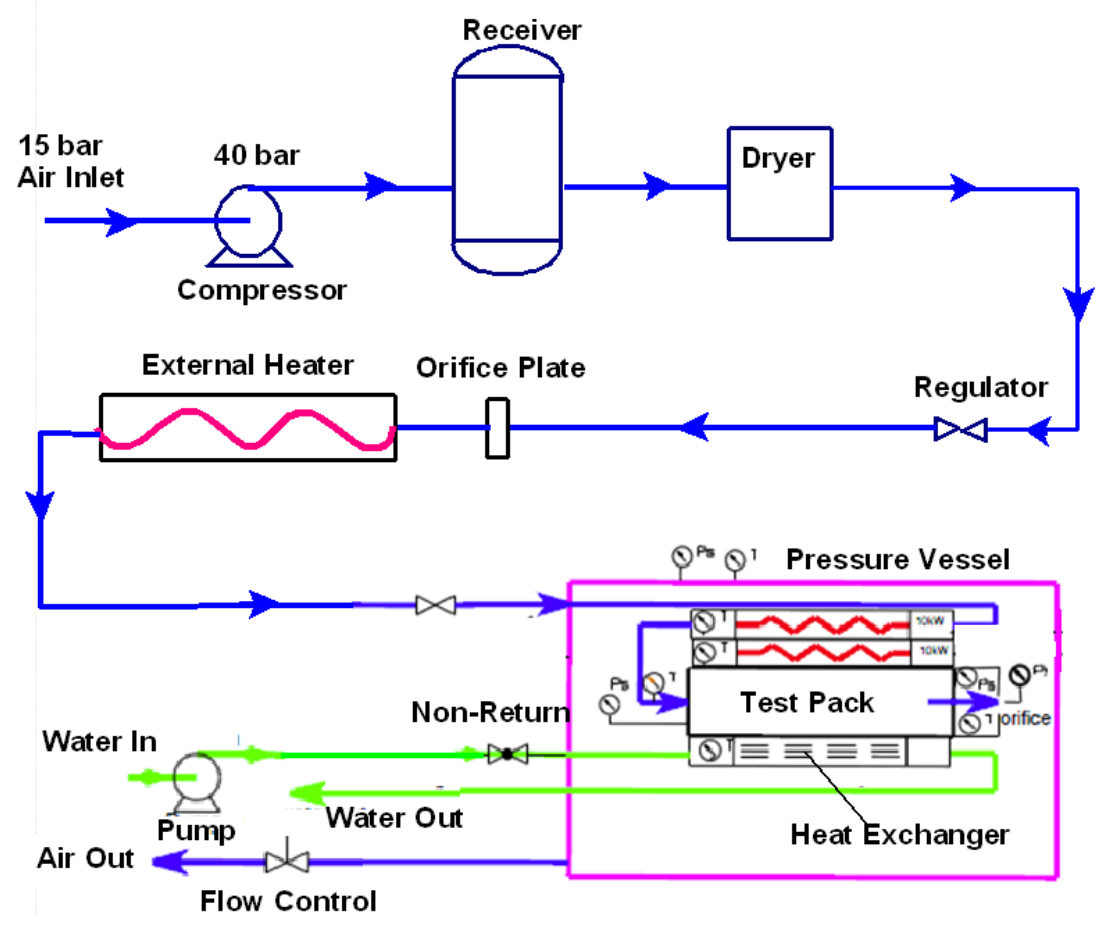

Figure 3. Schematic diagram of experimental facility

As shown in Figure 4, the insulation pack assembly is placed in a pressure chamber capable of operating at pressures up to $40 \mathrm{bar}$ and is sandwiched between an electrical heater at the top and a water-cooled aluminium plate below. A temperature difference of up to $500{ }^{\circ} \mathrm{C}$ can thus be maintained across the pack, by supplying thermal energy from above, through use of the electrical pack heater and removing it from below, through the use of the water-cooled aluminium plate. All sides of the pack heater box, apart from the lower side which is in contact with the pack, are thermally insulated, to ensure that most of the heat generated by the pack heater is absorbed by the top side of the insulation pack. Moreover, to further minimize heat losses from the top of the pack heater box, the gas heater, which as can be seen in Figures 4(a) and 4(b) is directly above the pack heater box, is maintained at the same temperature as the pack heater. The sides of the insulation pack are also thermally insulated, so that the thermal energy entering from the top is absorbed either by the cooling plate below, or the air flowing through the pack. The gas enters the pressure chamber from an inlet port on the left hand side, flows over the assembly and then through a gas heater which provides 
control of the gas temperature. It next flows through the pack, entering the pack section through three slots and exiting through an orifice.

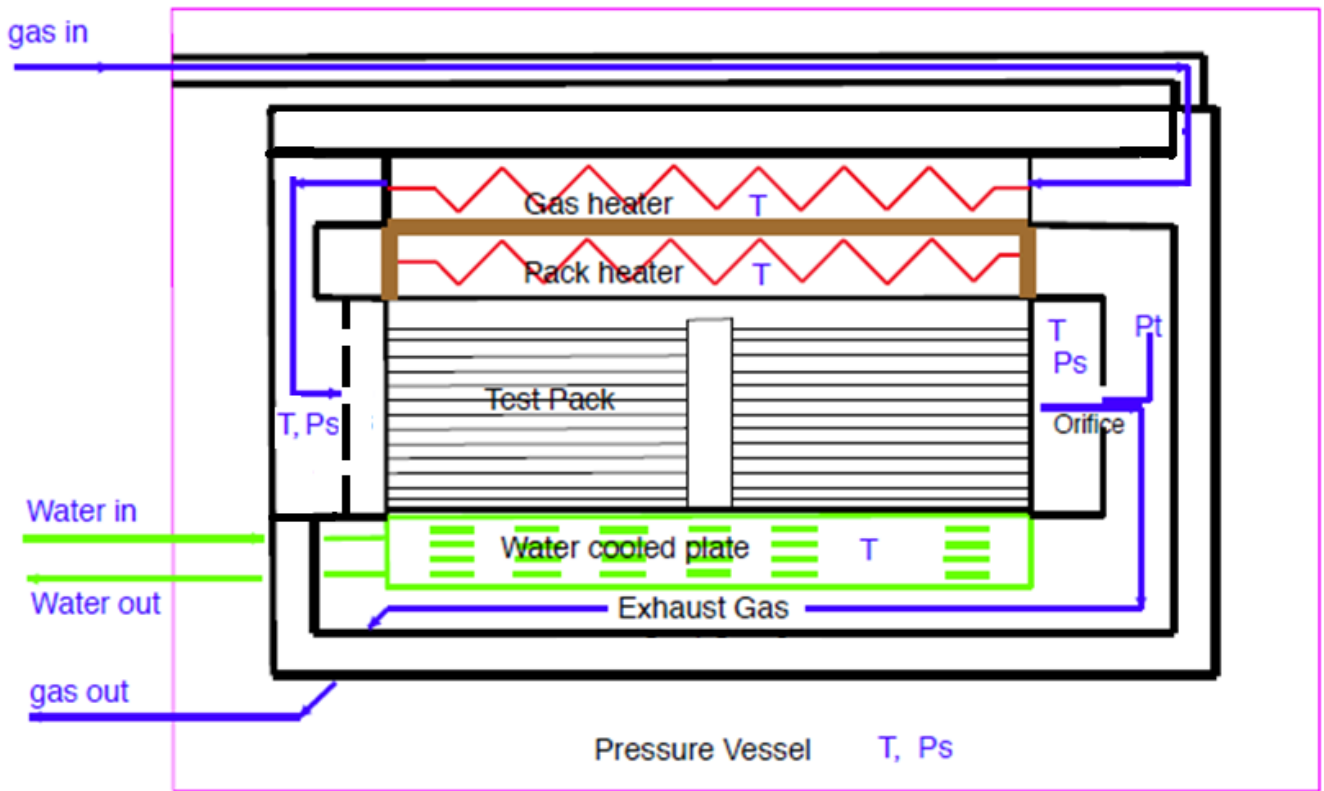

(a) Schematic diagram

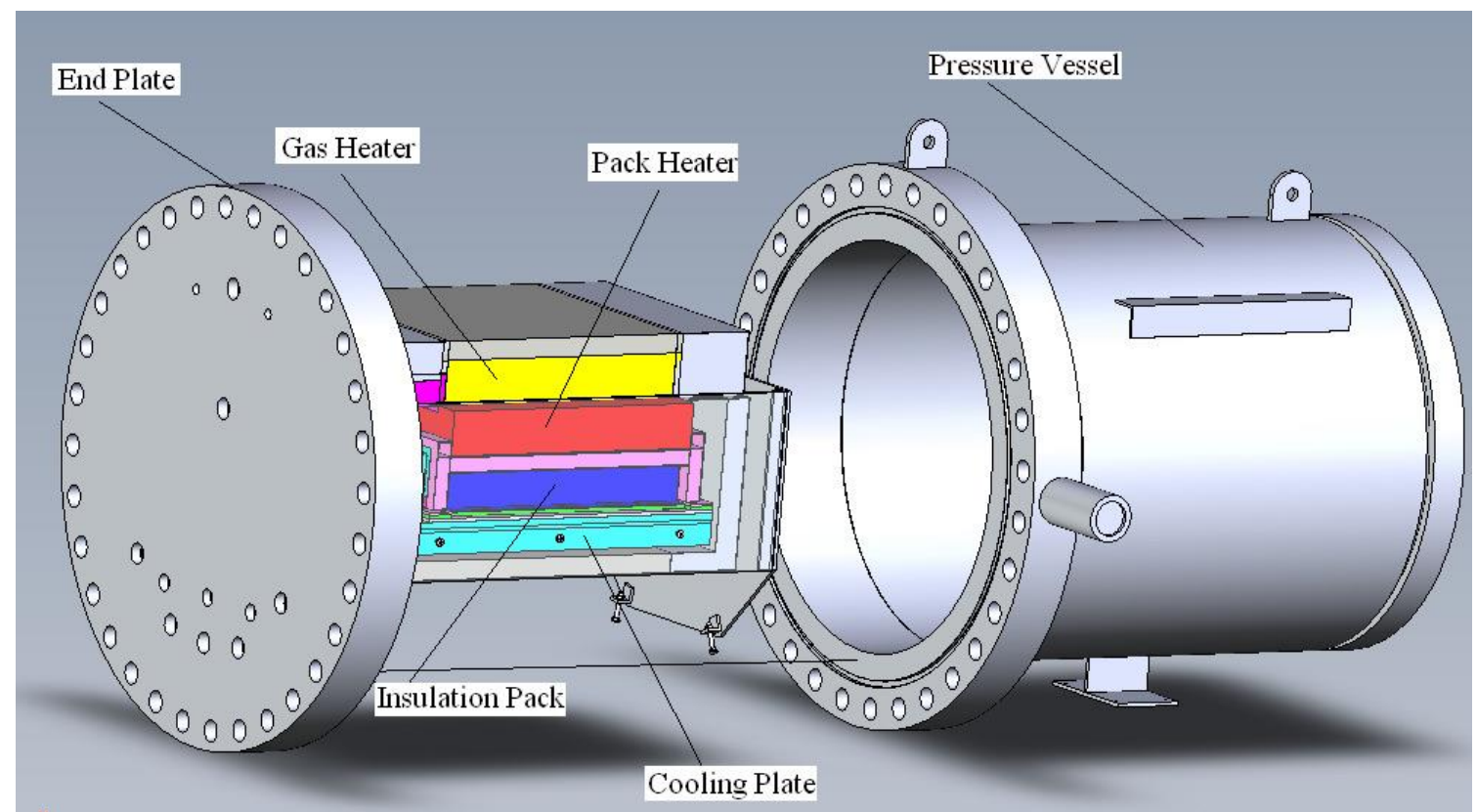

(b) Three-dimensional drawing 


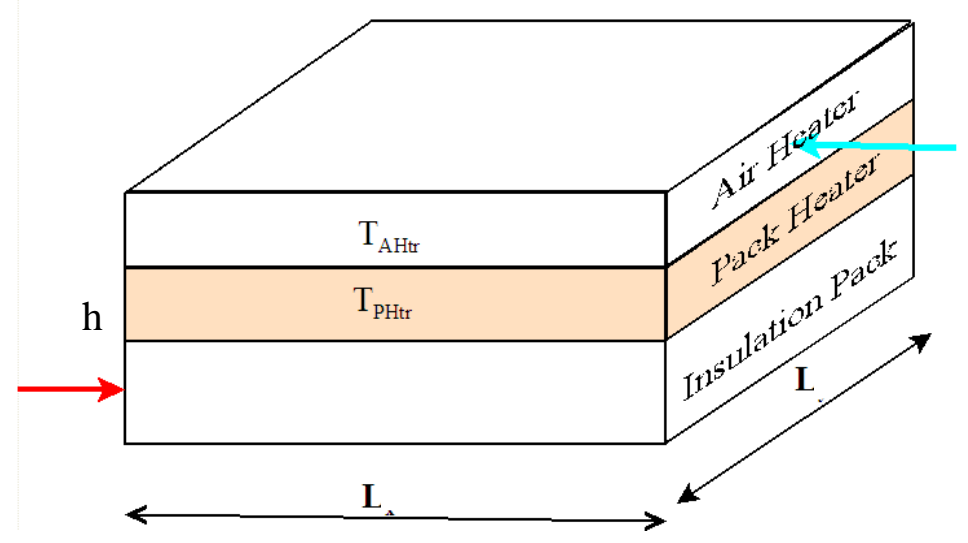

(c) Heater arrangement

Figure 4. Pressure vessel and pack assembly.

The gas then exits the pressure chamber. The locations of the thermocouples employed to monitor the temperature difference across the insulation pack and the temperature variation within it are shown in Figures 5 and 6. Over 70 thermocouples are deployed. Those located within the pack are miniature thermocouples, $0.5 \mathrm{~mm}$ in diameter, small enough to fit in the micro-channels between the foils. The rest are standard-size thermocouples. In addition to the thermocouples shown in Figures 5 and 6, standard ones are also used to monitor the gas temperature at the pack inlet and outlet, the temperatures of the pack and gas heaters, the temperatures of the sides of the pack heater and the temperature upstream of the orifice plate.

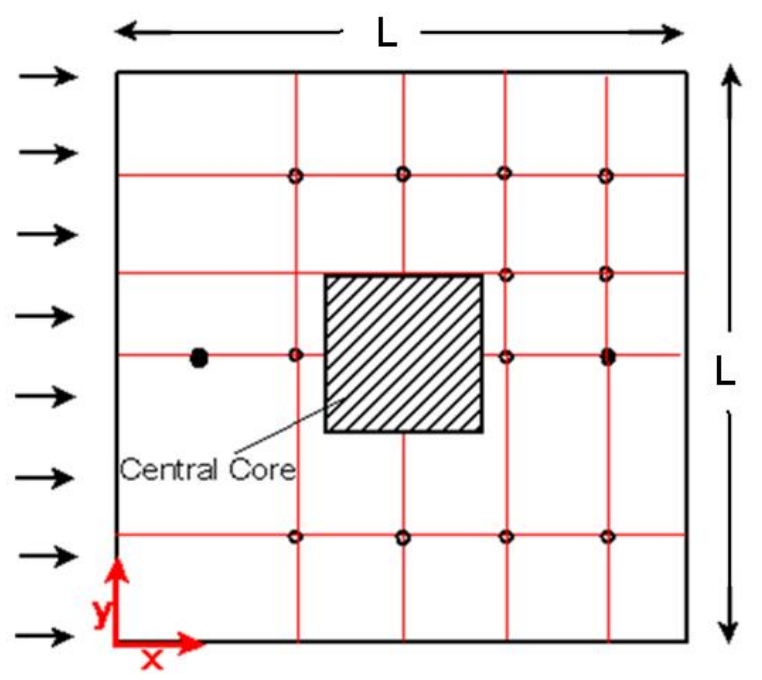

Figure 5. Top view of the locations of the insulation pack thermocouples 


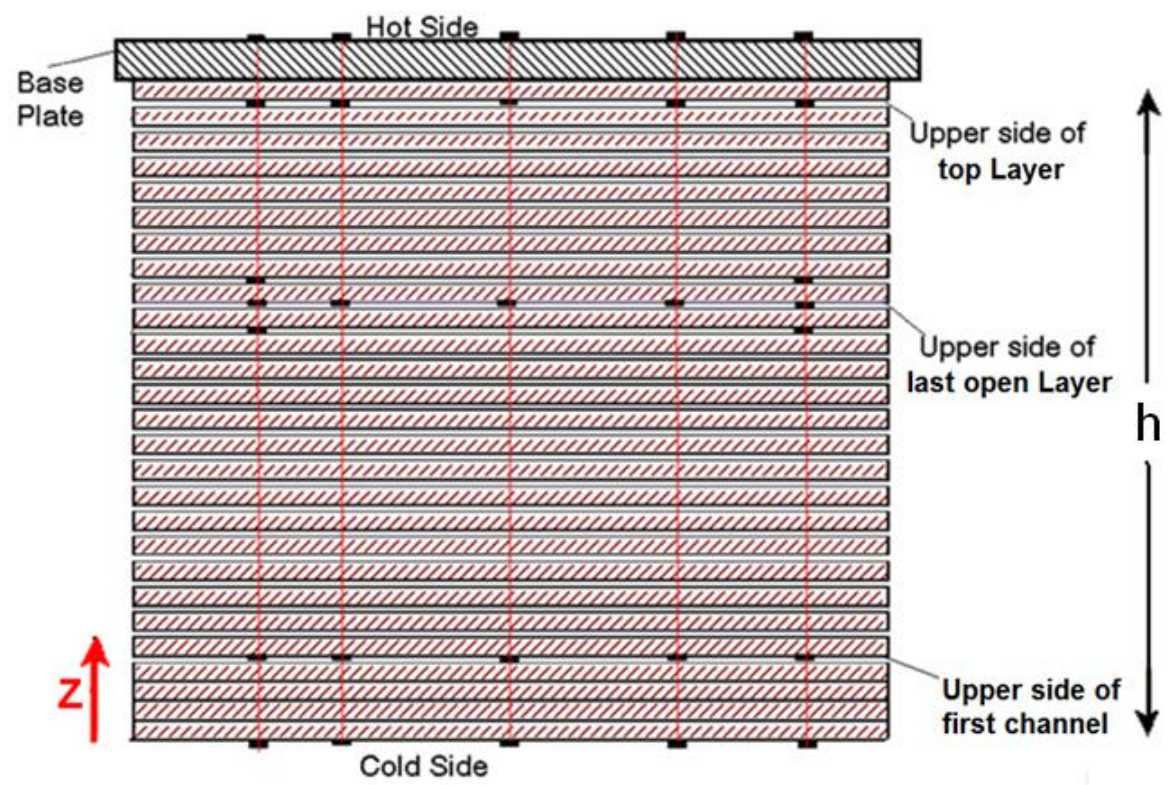

Figure 6. Side view of the locations of the insulation pack thermocouples

The static pressure within the system is also monitored at several locations. A differential pressure transducer suitable for absolute pressures of $40 \mathrm{bar}$ and of range from $1 \mathrm{mbar}$ to 1 bar, supplied by TechniMeasure Ltd is used to monitor the pressure difference across the orifice plate. Two further transducers also supplied by TechniMeasure Ltd, are used to monitor the static pressures upstream of the orifice and upstream of the insulation pack (inside the pressure chamber) respectively.

The lower flow rates investigated here, however, were outside the calibration range of the orifice plate standards and an alternative method was found. The Thermatel TA2 mass flow meter, based on thermal dispersion technology, which once calibrated, automatically compensates for changes in fluid pressure and temperature, over the low-flow rates required, was used in place of the orifice plate for tests carried out at low flow rates.

The electrical power produced by the pack heater (Figure 4), the value of which is needed for the calculation of the pack thermal conductivity, is accurately measured by using Memo 72-L intelligent power measurement units attached to the temperature controllers.

\section{Data Processing}

The pack effective conductivity, $k_{\text {eff, }}$, is defined in terms of the rate at which the lower (cold) surface of the pack absorbs thermal energy, $Q_{C}$, the pack thickness, $h$, and surface area, $A$, and the temperature difference across it, $\mathrm{Eq}(5) . Q_{\mathrm{C}}$ is determined from the difference between the power generated by the heater above the pack (corrected for heat losses), $Q_{H}$, and the rate at which the through flow gas gains or looses thermal energy. The latter is based on the gas flow rate, $m$ and pack inlet and outer temperatures, $T_{O U T}$ and $T_{I N}$, Eq(6).

$$
\begin{aligned}
& k_{\text {eff }}=h Q_{C} /\left[A\left(T_{H^{-}} T_{C}\right)\right] \\
& Q_{C}=Q_{H}-m c_{P}\left(T_{O U T}-T_{I N}\right)
\end{aligned}
$$


In order to calculate the losses from the pack heater box (see Fig 4(c)), meaning the amount of energy generated by the pack heater and not going into the insulation pack, there is a need to account for the rate at which energy escapes from the top surface to the gas heater box and also from the sides to the pressure chamber. This is done by making use of the measured values of the temperatures of the pack heater, the gas heater, and of the pack heater side walls. These heat losses through the side-walls were estimated by first calculating the convection and radiation thermal resistances between the pack heater and the inner walls of the heater box and adding them in parallel and then adding to them in series to the conduction resistance across the pack heater box side walls. Then the heat loss from the side walls can be obtained by dividing the known, from the measurements, difference between the temperatures of the pack heater and the outer surface of the heater box side-walls, by the thermal resistance between them. The total thermal resistance between the pack heater and the gas heater is also similarly calculated which allows for the heat loss to the gas heater to be estimated by dividing the known difference between the two heater temperatures by the total thermal resistance between them. In fact the heat loss from top of the pack heater box, is reduced to insignificantly low levers by adjusting the air heater temperature to be the same as that of the pack heater, thereby eliminating the temperature difference across the top side of the pack heater box. The resulting calculations show that on average the total heat loss of about $15 \%$ of input power.

Dimensional analysis shows that the effective conductivity of the pack, normalized by the molecular conductivity or air, $k$, in general depends on the following dimensionless groups:

$$
k_{e f f} / k=f\left(\operatorname{Re}_{\delta}, R a_{\delta}, T_{I N}^{*}, \theta\right)
$$

Table 1 Dimensionless Groups

\begin{tabular}{|l|l|l|}
\hline Symbol & Name & Definition \\
\hline $\mathrm{Re}_{\delta}$ & Reynolds number & $R e_{\delta}=\rho U_{B} \delta / \mu$ \\
\hline $\mathrm{Ra}_{\delta}$ & Rayleigh & $R a_{\delta}=g \beta\left(T_{H}-T_{C}\right) \delta^{3} P r / v^{2}=\rho^{2} g \beta\left(T_{H}-T_{C}\right) \delta^{3} P r / \mu^{2}$ \\
\hline$T_{I N}^{*}$ & Normalized Inlet Temp. & $T_{I N}{ }^{*}=\left(T_{I N^{-}} T_{C}\right) /\left(T_{H^{-}} T_{C}\right)$ \\
\hline$\theta$ & Angle to the horizontal & \\
\hline
\end{tabular}

Here, $\delta$ is the ratio between the pack surface area and its open perimeter, $U_{B}$ is the bulk velocity, $\beta$ is the coefficient of volumetric expansion and Pr the Prandtl number of air.

\section{Experimental Uncertainty}

The primary measurements involved in this investigation include thermocouple measurements, differential pressure measurements across the orifice plate and electrical power measurements. The thermocouples were calibrated using a calibrator suitable for the range of temperatures involved, to an accuracy of $\pm 0.1^{\circ} \mathrm{C}$. The orifice plate differential transducer has an accuracy of \pm 0.003 bar and the measurements of the electrical power supplied have an uncertainty of $\pm 1 \%$. These uncertainties in the primary measurements lead to the uncertainties in the parameters which result from the post-processing of the primary data, summarised in Table 2 .

Table 2. Experimental Uncertainties 


\begin{tabular}{|l|c|c|c|}
\hline Parameter & Reynolds Number & Rayleigh Number & Effective Conductivity \\
\hline Uncertainty & $\pm 3.0 \%$ & $\pm 1,6 \%$ & $\pm 7.6 \%$ \\
\hline
\end{tabular}

\section{Experimental Results and Discussion}

Close to 90 tests have been carried out, some without imposed flow at pressures ranging from 1 to 40 bar, for horizontal and inclined orientations. Most tests have been with imposed flow. In all these tests the difference between the top hot side and the bottom cold side temperatures ranged from $200^{\circ} \mathrm{C}$ to $450^{\circ} \mathrm{C}$.

Consider first the pack held horizontally in the absence of any imposed flow. In Figure 7 the effective thermal conductivity, normalized by the thermal conductivity of air, is plotted against the Rayleigh number, which depends primarily on pressure. The plot shows that the data collapse along a single line, which suggests a monotonic rise of the effective conductivity with Rayleigh number. If heat conduction was the only, or predominant, mode of heat transfer across the pack, then given that the thermal conductivity of gases is independent of pressure, which is the property that changes the most in these tests, the effective conductivity would be expected to remain constant. The only conclusion is that the difference in temperature between the top and bottom plates generates buoyancy-driven motion, which then transports thermal energy across the insulation pack. This outcome was not expected, given that the spacing between the steel foils within the pack is less than $1 \mathrm{~mm}$.

As noted earlier, natural convection heat transfer to a single upward-facing cool plate placed in a stagnant warmer fluid environment is given by equation (1). Combination of equation (1) with the definition of the effective thermal conductivity of equation (5) leads to

$$
\frac{k_{\text {eff }}}{k}=\frac{h}{\delta} 0.27 R a_{\delta}^{0.25}
$$

Equation (8) is also plotted in Figure 7. It should be emphasised that equation (8) has been proposed for a different and simpler thermal system than the one investigated here. It is included here for only qualitative comparisons, because among the experimental studies on natural convection found in the literature, this is for a system closest to the one examined here. Agreement with the data is surprisingly good, particularly at the lower Ra range. This supports the proposition that buoyancy-driven motion is responsible for the increase in effective conductivity with pressure.

Having established that for horizontal no-flow conditions the effective conductivity is strongly influenced by buoyancy, the next question is what happens with imposed flow. Figure 8 shows that there is a considerable increase in effective conductivity with Rayleigh number. In contrast to the no-flow graph of Figure 7, however, there is now considerable scatter. This suggests that the Reynolds number also exerts an influence, a hypothesis that is confirmed by the 3-dimensional graph of Figure 9, in which the effective conductivity is plotted against both the Rayleigh and Reynolds numbers. Figure 9 demonstrates that the influences of forced and natural convection across the insulation pack are comparable. 


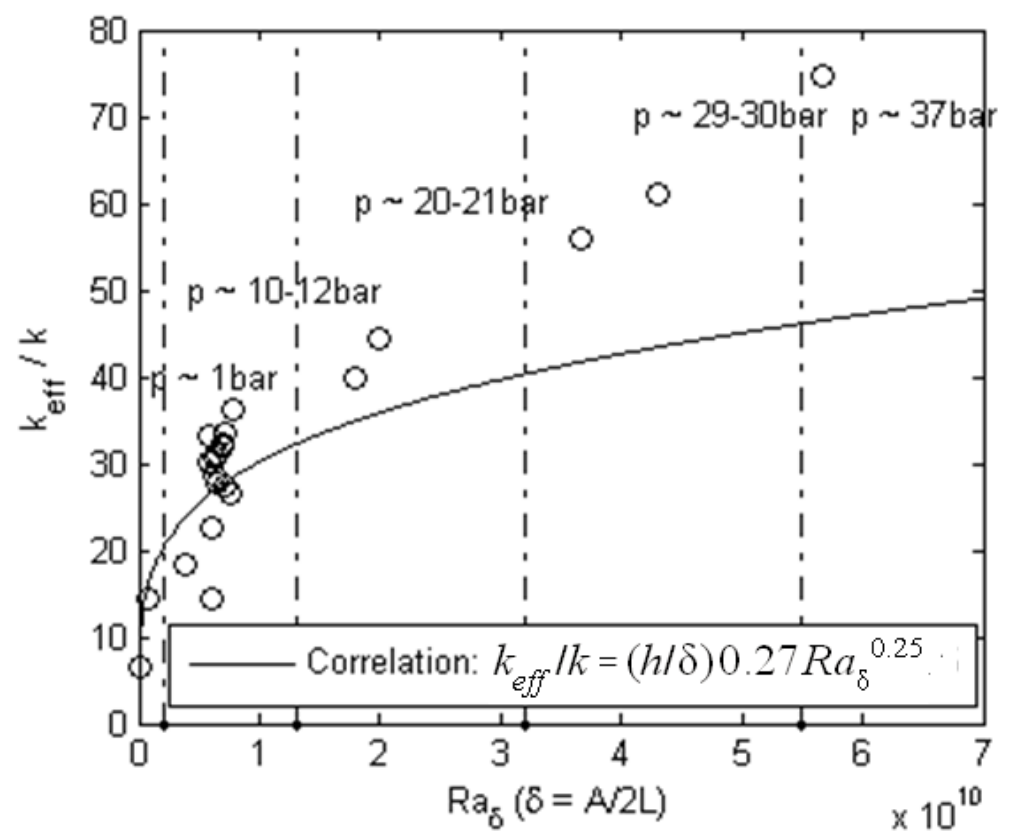

Figure 7. Effective conductivity against Rayleigh number, for horizontal pack and no imposed flow. The continuous line denotes the correlation of Fishenden and Saunders [6], for a single cool upward facing plate in a warm quiescent environment.

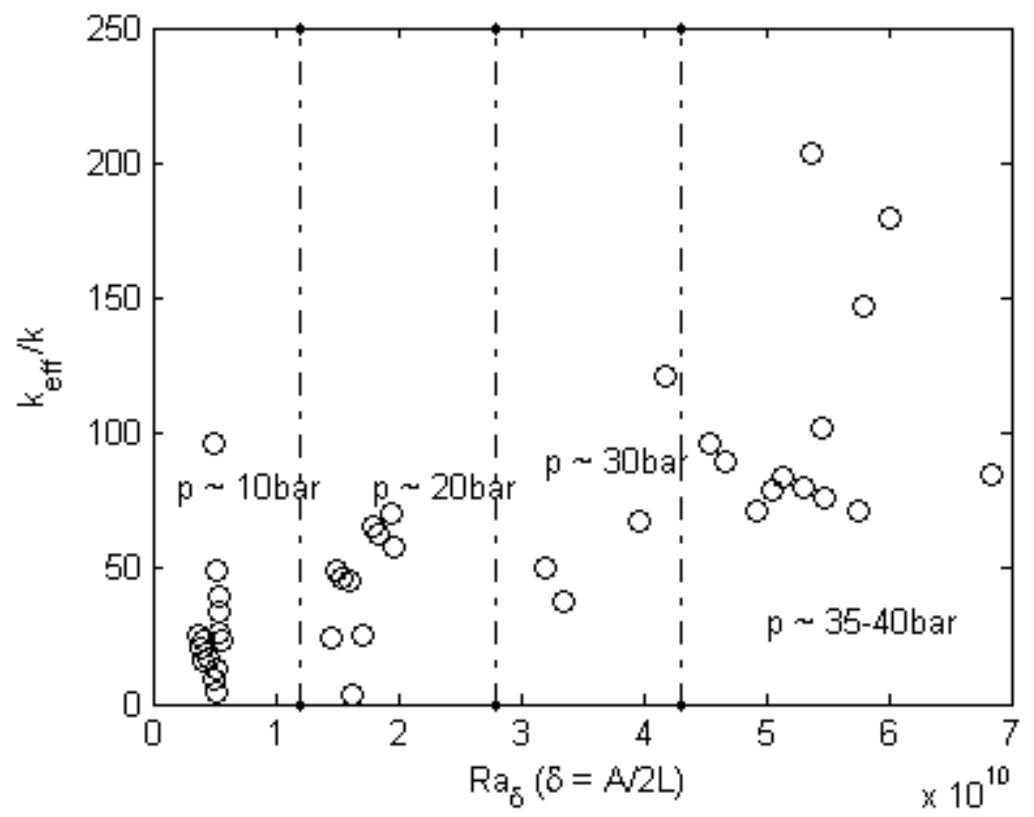

Figure 8. Effective conductivity against Rayleigh number for horizontal pack with imposed flow

A plot of the effective conductivity against the normalized inlet temperature, on the other hand (not included here), showed no obvious correlation between these two parameters. A possible explanation for this unexpected outcome can be provided by a graph of the outlet normalized temperature against the inlet one (Figure 10). As expected, it shows an overall increase of the former with the latter, but, more importantly, it also shows that most of the data lie below the $45^{\circ}$ line. This means that in the majority of cases the air loses thermal energy as it flows through the pack, although it often enters at a relatively low temperature. 
This result suggests that in most cases the heat transfer coefficient along the lower side is higher than that along the top side. This in turn might explain why the pack effective conductivity, which focuses on the rate of heat transfer to the lower side, is more sensitive to changes that affect the flow, rather than to thermal inlet conditions.

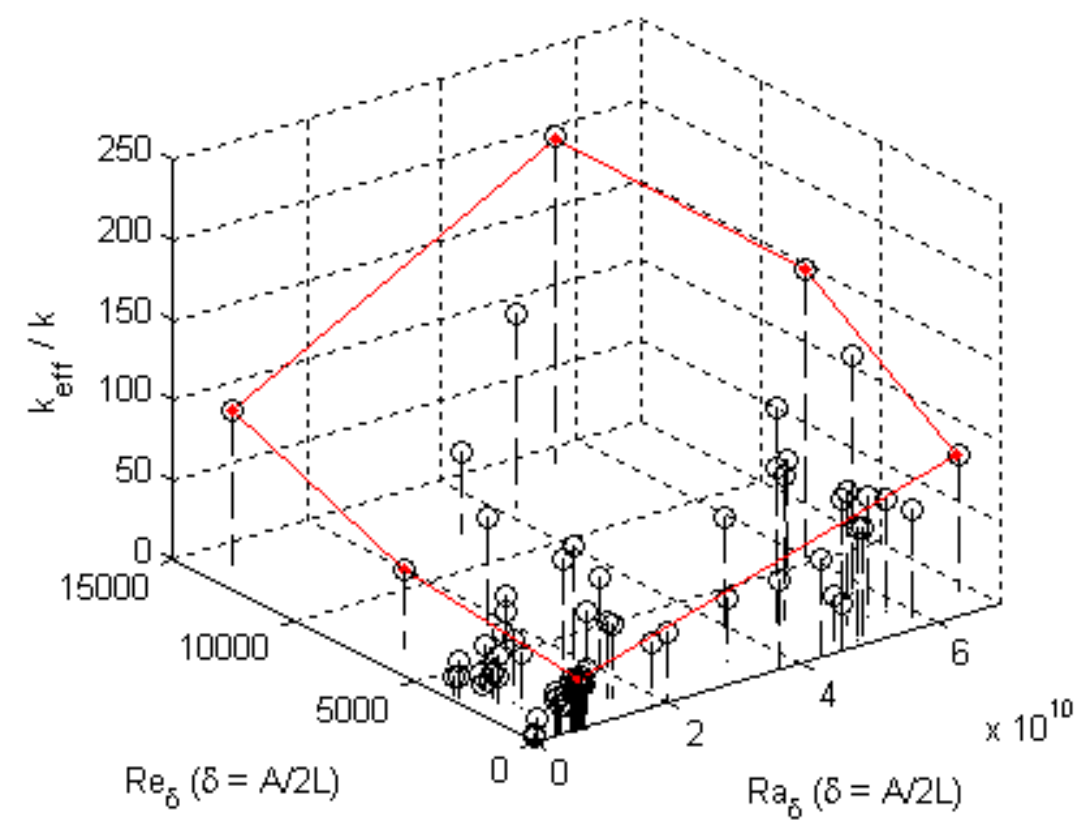

Figure 9. Effective conductivity against Reynolds and Rayleigh numbers for horizontal pack

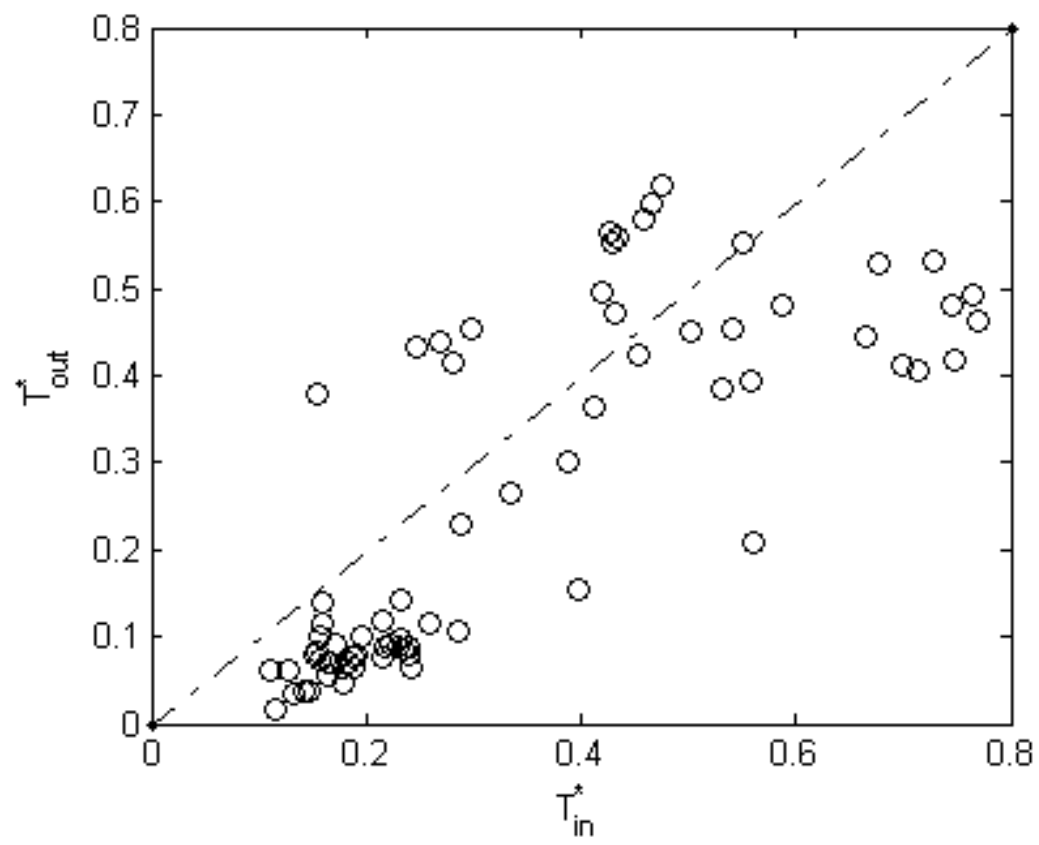

Figure 10. Normalized outlet against normalized inlet temperature for horizontal case

Having established that buoyancy effects are significant, even for horizontal orientation with imposed flow, it must be expected that buoyancy will have a stronger effect when the pack is inclined, even at angles as low as $10^{\circ}$ to $30^{\circ}$. The influence of the angle of inclination on the 
effective conductivity, and hence on the heat transfer rate to the cold side of the pack, is shown in Figure 11. Two features can be observed:

- There is a monotonic rise in the effective conductivity with angle of inclination, even at no-flow conditions.

- The effects of angle of inclination become stronger at higher pressures and at higher Reynolds numbers (e.g. Re increases from the curve identified with the symbol "**" to that identifies with the symbol " $\Delta$ " in Figure 11).

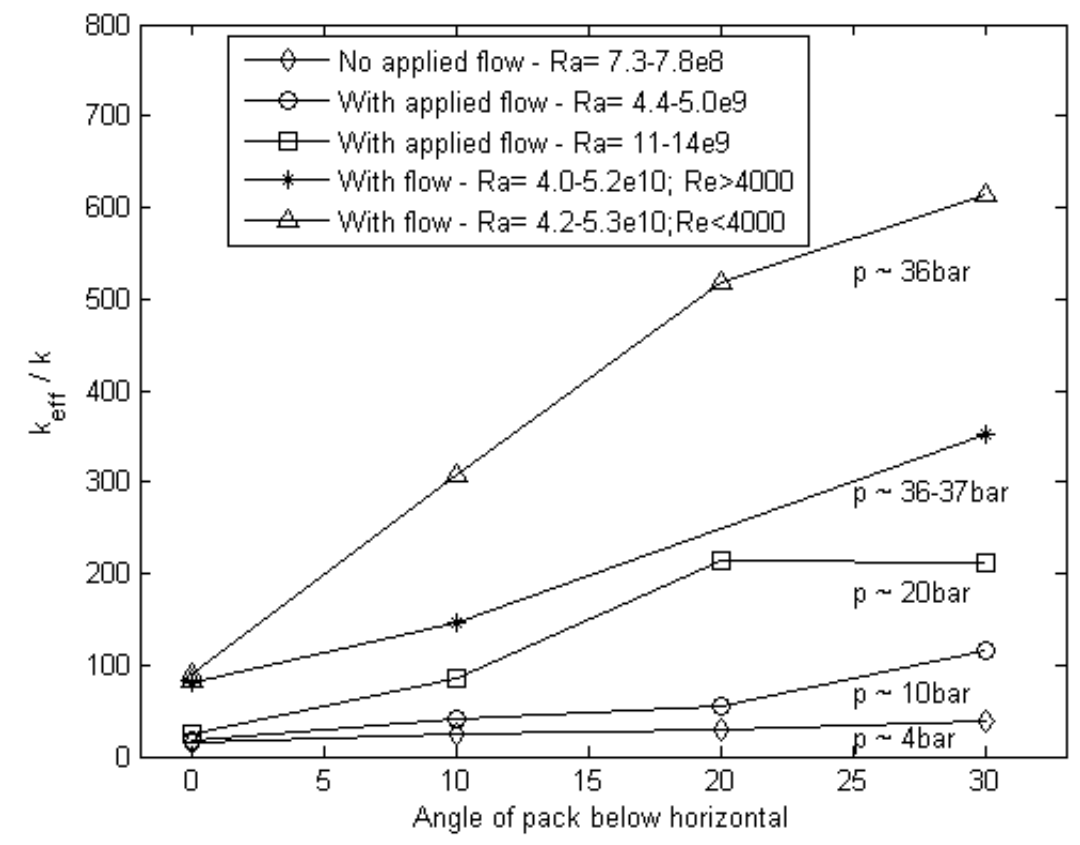

Figure 11.Effect of angle of inclination on effective conductivity

While these two observations are entirely consistent with the findings of the horizontal pack tests, the magnitude of the effect of inclination on the effective conductivity is both surprising and significant. Even at $10^{\circ}$, the effective conductivity is augmented by a factor of 4 , in comparison to that for a horizontal pack. This means that, even if this experimental setup augments the reactor effects of inclination on heat transfer, any analysis of flow in micro-channels at such pressures and temperature scales must include buoyancy.

The effective conductivity data highlighted the trends in the variation of the overall heat transfer. The measurements of the temperature variation across the insulation pack provide further insight to the processes involved. A representative number of comparisons of the temperature profiles across the insulation pack has been included, focusing on two lateral planes, $y / L=0.167$ and $y / L=0.5$, presented in Figure 12. Figure 12(a) examines no-flow conditions for a horizontal pack, at two Rayleigh numbers, controlled through the pressure. The profiles, for the lower Rayleigh number of $5.1 \times 10^{7}(1$ bar $)$, show a nearly linear temperature variation. This suggests that the effects of any buoyancy-induced motion on the heat transfer across the pack are weak. At the higher Rayleigh number of $3.54 \times 10^{10}$, on the other hand, the temperature variation is non-linear, with very steep temperature gradients near the hot plate. This provides further evidence that at higher Rayleigh numbers the transfer of 
thermal energy is influenced by convection. Moreover, there is little difference in the variation in temperature at the two lateral locations $(y / L=0.167$ and $y / L=0.5)$, which suggests that there is little lateral variation in thermal conditions. As expected the profiles of Figures 12(b) and 12(c), for a horizontal pack with imposed flow, show an even more highly non-linear variation, in comparison to the no-flow cases. In addition, Figure 12(b) shows that there is a further, but small deviation from linearity with Reynolds number, while in Figure 12(c) the increase in Rayleigh number has a stronger effect on temperature variation across the pack. These findings confirm how influential natural convection effects are, even for a horizontal pack. As also noted for the no-flow case, thermal conditions change little in the lateral direction.

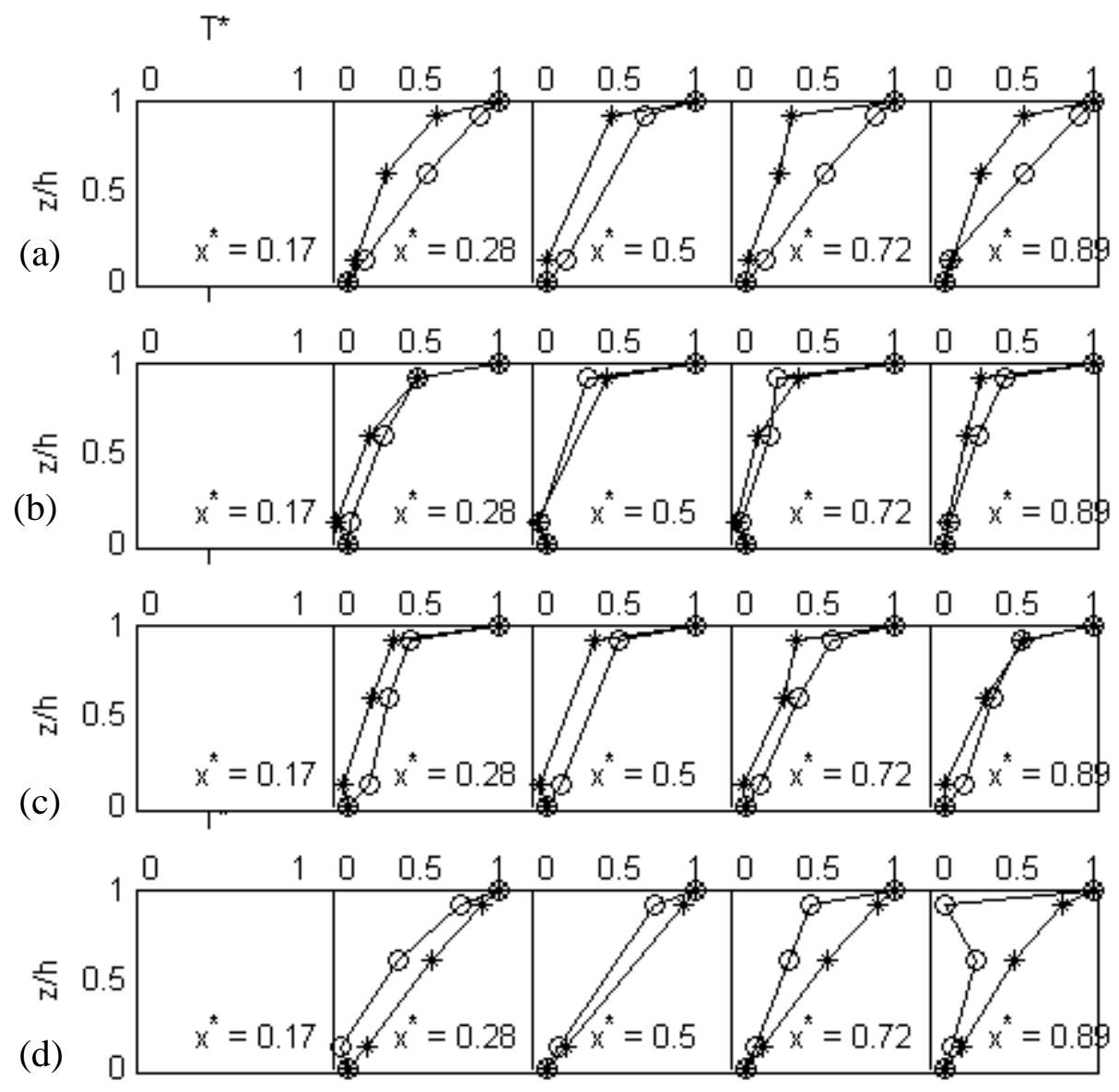

Figure 12. Profiles of the local normalized temperature, $T^{*} \equiv\left(T-T_{C}\right) /\left(T_{H}-T_{C}\right)$, along vertical planes, at $\mathrm{y} / \mathrm{L}=0.167$, with $\mathrm{x} * \mathrm{x} / \mathrm{L}$.

(a) No flow, O Ra $=5.1 \times 10^{7}$, * $\mathrm{Ra}=3.54 \times 10^{10}$

(b) Imposed flow, $\mathrm{ORe}=1.42 \times 10^{4}, \mathrm{Ra}=5.4 \times 10^{10}, * \quad \mathrm{Re}=1.29 \times 10^{3}, \mathrm{Ra}=5.49 \times 10^{10}$

(c) Imposed flow, $\mathrm{ORe}=3.03 \times 10^{3}, \mathrm{Ra}=5.64 \times 10^{9}, * \mathrm{Re}=2.84 \times 10^{3}, \mathrm{Ra}=5.83 \times 10^{10}$

(d) No flow, $\mathrm{O} \theta=0^{\circ}, \mathrm{Ra}=7.34 \times 10^{8}, * \theta=30^{\circ}, \mathrm{Ra}=7.61 \times 10^{8}$ 

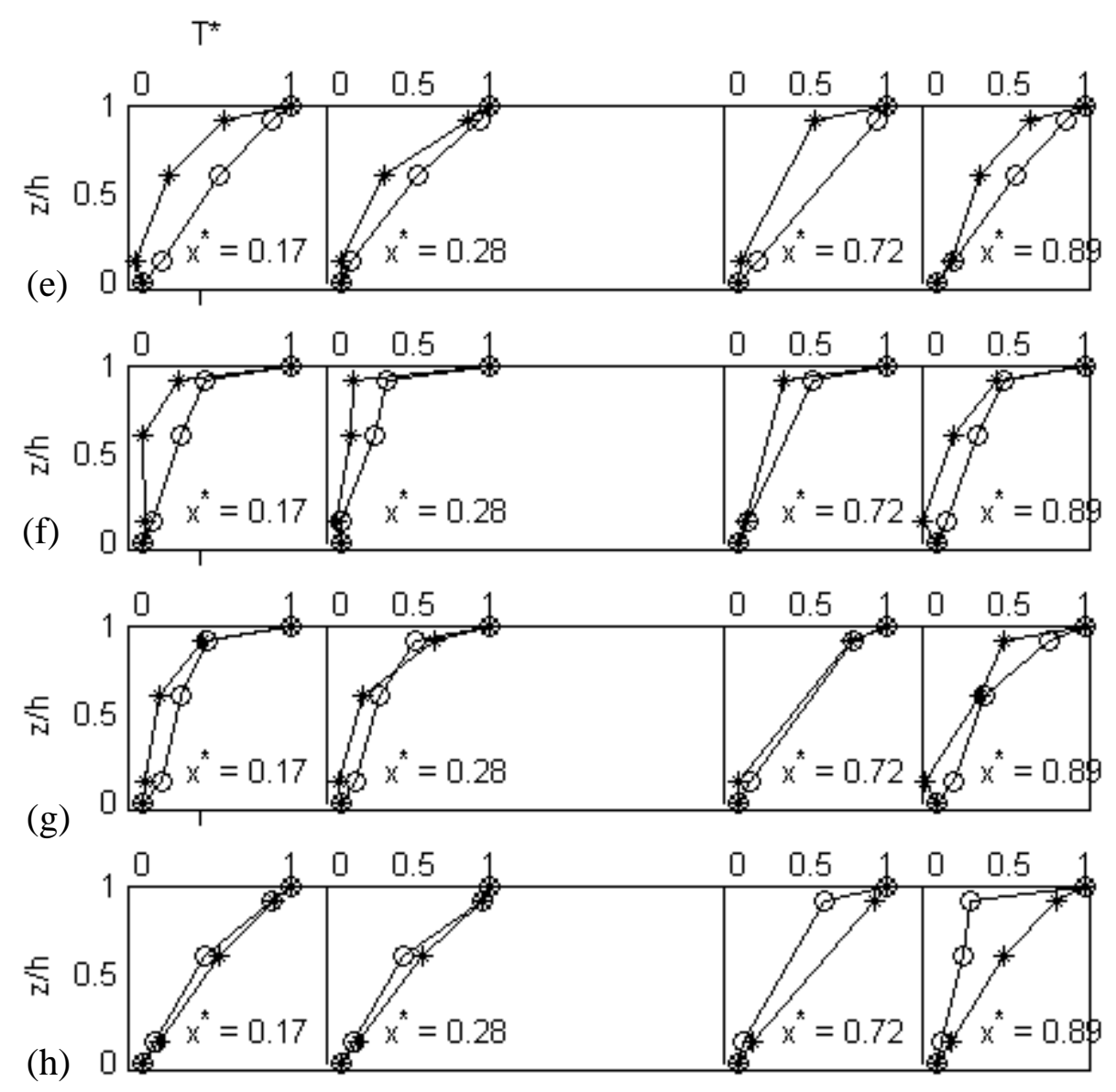

Figure 12. Profiles of the local normalized temperature, $T^{*} \equiv\left(T-T_{C}\right) /\left(T_{H}-T_{C}\right)$, along vertical planes, at $\mathrm{y} / \mathrm{L}=0.5$, with $\mathrm{x}^{*} \equiv \mathrm{x} / \mathrm{L}$.

(e) No flow, $\mathrm{O} \mathrm{Ra}=5.1 \times 10^{7}, * \quad \mathrm{Ra}=3.54 \times 10^{10}$

(f) Imposed flow, ORe $=1.42 \times 10^{4}, \mathrm{Ra}=5.4 \times 10^{10}, * \mathrm{Re}=1.29 \times 10^{3}, \mathrm{Ra}=5.49 \times 10^{10}$

(g) Imposed flow, ORe $=3.03 \times 10^{3}, \mathrm{Ra}=5.64 \times 10^{9}, * \mathrm{Re}=2.84 \times 10^{3}, \mathrm{Ra}=5.83 \times 10^{10}$

(h) No flow, $\mathrm{O} \theta=0^{\circ}, \mathrm{Ra}=7.34 \times 10^{8}, * \theta=30^{\circ}, \mathrm{Ra}=7.61 \times 10^{8}$

For the inclined case with no through flow, Figure 12(d) compares local temperature profiles under horizontal, $\theta=0^{\circ}$, and inclined, $\theta=30^{\circ}$, conditions. The influence of the angle of inclination on local temperature is very strong, especially in the downstream region. This is consistent with the presence of an upward, buoyancy-driven motion along the top wall. Given that the preceding comparisons show that flows in a horizontal pack, even with imposed flow, are influenced by buoyancy, it would be reasonable to expect that such effects will be even stronger in the inclined cases. Again there does not appear to be a significant lateral variation in the temperature distribution across the pack. For the inclined pack cases with imposed through-flow, the temperature measurements, not included here, show a strong change in the cover plate temperature along the flow direction, which in turn suggests a strong variation in the coefficient of wall heat flux along the top surface. Consequently, comparisons between the profiles of the dimensionless temperature obtained from tests with inclined insulation packs with through flow and those of other tests, in which the cover plate remains practically isothermal, are not very meaningful. 


\section{Numerical Study}

Due to the lack of experimental data on the velocity field within the pack, a limited numerical study was also undertaken, looking at a simplified two-dimensional numerical model of the experimental setup. The objective has not been to carry out quantitative comparisons with the experimental data, but simply to improve our understanding of the flow physics involved.

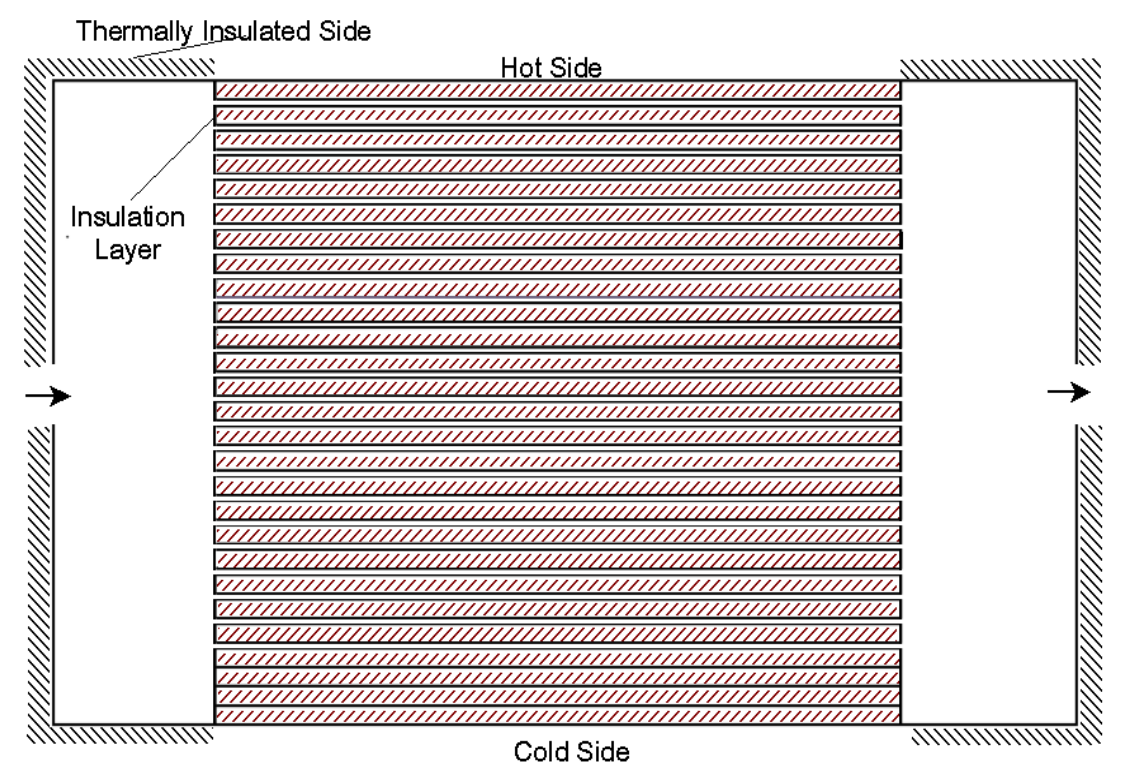

(a) Pack with uninterrupted foils

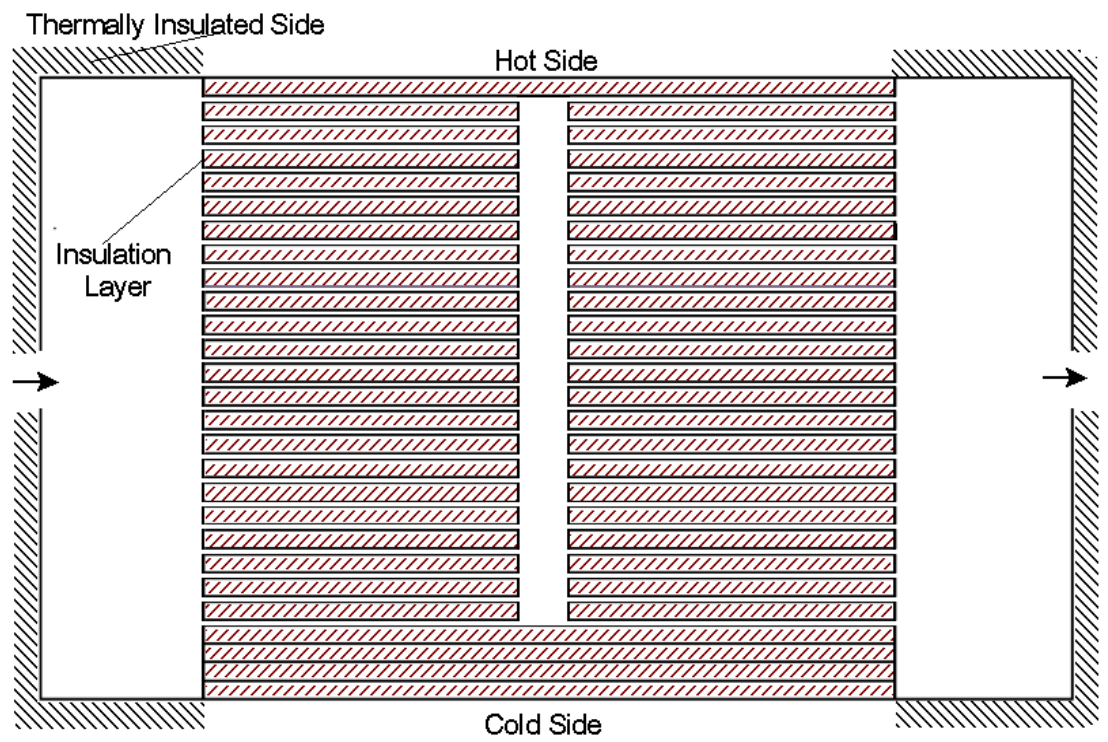

(b) Pack with a central hole.

Figure 13. Two-dimensional numerical models of the experimental set-up (not to scale)

Flow is assumed to be laminar. The computations involve conjugate heat transfer analysis, mostly of the domain shown in Figure 13(a). The shaded areas within the solution domain denote the foils and are treated as solid blocks. The dimensions of the solid blocks and the 
width of the micro channels formed between them are the same as those given in Figure 2. Fluid properties are temperature dependent for air at 40 bar. The thermal properties of the solid blocks are the effective properties of an air-filled block with a stainless steel outer skin. The hot side temperature, $T_{H}$ was set to $400{ }^{\circ} \mathrm{C}$ and the cold side one, $T_{C}$, at $30^{\circ} \mathrm{C}$. In imposed flow cases the mass flow rate corresponds to the low end of the range of the experimental flow rates and the inlet temperature to the average of $T_{H}$ and $T_{C}$. Computations were also obtained for the alternative flow domain shown in Figure 13(b), in which a central hole is introduced to mimic the presence of the central core in the experiments.

An in-house two-dimensional, finite-volume code has been employed. It is an incompressible flow code, based on the SIMPLE algorithm and using the HYBRID for the discretisation of convective transport. The flow domain was covered by 401x1667 grid nodes in the flow $(x)$ and cross-pack $(z)$ directions respectively. Each micro channel is resolved with 16 control volumes. The foil regions are treated as solid blocks in the solution of the Navier-Stokes equations, while the enthalpy transport equation is solved throughout, but in the control volumes within the foils, with zero velocities and different thermal conductivity values. The gravitational force is also included in the momentum equations, in a direction which is either normal, or at $60^{\circ}$ to the flow direction, which corresponds to the $30^{\circ}$ inclination of the experimental investigations.

Predictions in horizontal packs with no imposed flow are shown in Figure 14. For the pack with uninterrupted foils, in contrast to the experimental findings, a very weak buoyancy-driven motion is predicted, which has little effect on the temperature variation. Introduction of a central hole enhances the buoyancy-driven motion, and temperature profiles start to become non-linear. The predicted buoyancy effects, however, are not as strong as those suggested by the experiments. A possible explanation is that there are lateral recirculation cells in the micro-channels of the insulation pack, such as those found in Cooper et al [15], which the two-dimensional simulations cannot reproduce.

Inclination, as can be seen in Figure 15, in the no-flow cases, 15(a) and 15(b), causes a strong re-circulation pattern, with upward fluid motion along the hot side and downward along the cold side. Because of the strong density change across the pack, in order to satisfy mass conservation, in Figure 15(a), the downward velocity associated with the denser gas is lower than the upward velocity of the lighter fluid. The temperature field and consequently heat transfer are strongly affected by convection. The predicted temperature profiles (Figure. 15(b)) become non-linear with steep gradients along both sides. There are similarities with the corresponding measured profiles of Figure 12(d). Even with imposed flow, the buoyancy-driven recirculation pattern still remains, but the downward motion is now stronger The temperature gradients along the lower side consequently become steeper, which is consistent with the increase in the measured thermal conductivity presented in Figure 11. The predicted flow behaviour in inclined insulation packs is consistent with the corresponding measurements and consequently supports the earlier conclusions. 


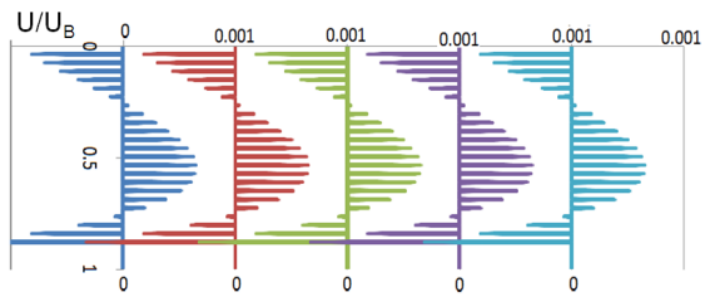

(a) Velocity, pack with uninterrupted foils.

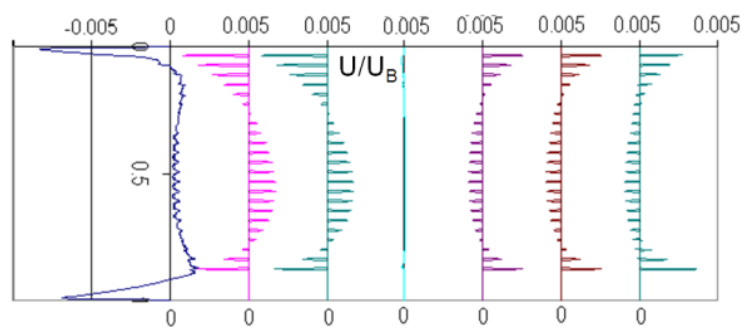

(c) Velocity, pack with central hole

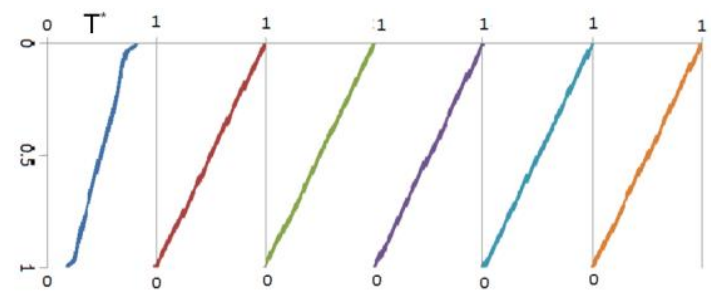

(b) Temperature, pack with uninterrupted foils.

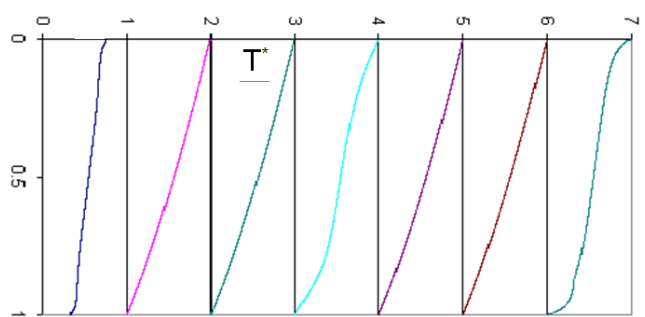

(d) Temperature, pack with central hole.

Figure 14.Profile predictions for no flow case in a horizontal pack.

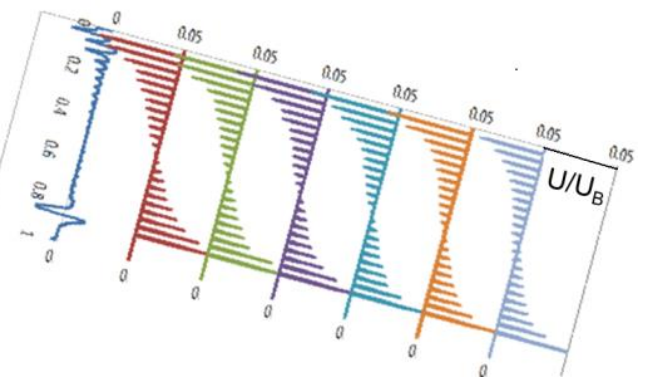

(a) Velocity, pack with no through flow.

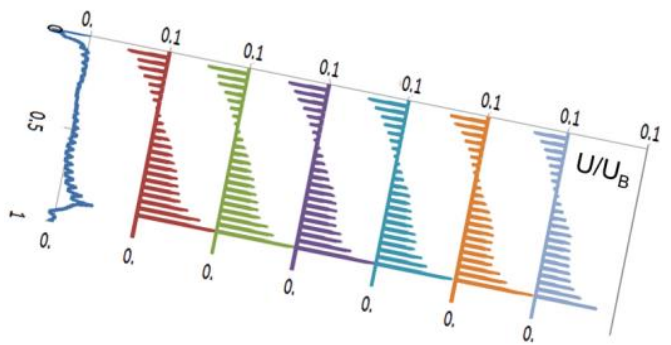

(c) Velocity, pack with through flow.

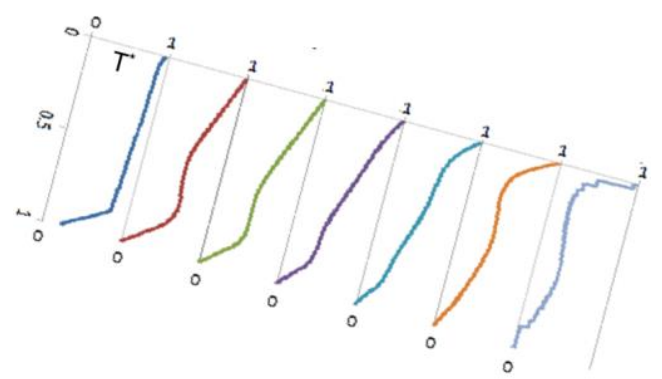

(b) Temperature, pack with no through flow.

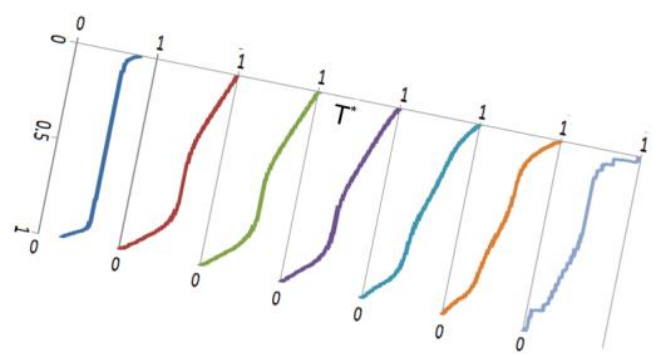

(d) Temperature, pack with through flow.

Figure 15.Profile predictions for an inclined pack.

\section{Concluding Remarks}

The main focus of this study has been the experimental investigation of the effects of extreme pressure and temperature differences on conjugate heat transfer across an insulation pack which consists of a series of adjacent micro channels. A specialist experimental facility has been developed for this purpose. The high operating pressure and temperature difference 
provided a unique opportunity to explore and quantify the effects of Reynolds and Rayleigh numbers and of orientation, for a range of dimensionless values far wider than would normally be possible for a pack of this size.

The most striking feature of the effective conductivity measurements is how important the effects of buoyancy-driven motion become at the high pressures and temperature differences at which these tests have been carried out, even though the channels present within the insulation pack are less than $1 \mathrm{~mm}$ wide. These buoyancy effects, which are markedly enhanced by even modest angles of inclination, are also evident in the measured temperature profiles across the pack. For the inclined pack, conjugate heat transfer simulations for a simplified two-dimensional model are consistent with the measured behavior, while for the horizontal case the two-dimensional simulations fail to predict significant buoyancy effects, It is hypothesized that the latter is due to the presence of lateral buoyancy driven structures in the horizontal cases, which the two-dimensional simulations are unable to reproduce.

\section{Acknowledgements}

The work reported here was supported by EDF-Energy (Barnwood, Gloucester, UK). The authors are. particularly pleased to acknowledge the technical input of Dr. Steve Fairbairn, Dr. Mike Rabbitt and Mr. Chris Sigournay, all of EDF-Energy

\section{References}

[1].J.P. Holman, Heat Transfer, 9th edition, McGraw-Hill, (2002).

[2].F. P. Incropera, D. P. DeWitt, T. L. Bergman, A. S. Lavine, Fundamentals of Heat and Mass Transfer, 6th ed, Wiley, Hoboken, New Jersey, (2007).

[3].A. Bejan, Heat Transfer. Wiley, New York,(1993).

[4].T. Cebeci, Convective Heat Transfer. 2nd ed., Horizons Publishing, Long Beach, California/Springer-Verlag, Berlin. (2002).

[5]. Y. Jaluria, Natural Convection. Heat and Mass Transfer. Pergamon, Oxford. (1980).

[6].M. Fishenden, O. A. Saunders, An Introduction to Heat Transfer. Oxford University Press, London, (1950).

[7].W. H. McAdams, Heat Transmission. 3rd ed., McGraw-Hill, New York,( 1954).

[8].R. J..Goldstein, E. M. Sparrow, D. C. Jones, Natural convection mass transfer adjacent to horizontal plates. Int. J. Heat Mass Transfer, 16, (1973)1025-1035.

[9].H.-T. Lin, C.-C. Chen, W.-S. Yu, Mixed convection from a horizontal plate to fluids of any Prandtl number. Wärme- und Stoffübertragung, 24, (1989) 225-234.

[10].X. A. Wang, An experimental study of mixed, forced, and free convection heat transfer from a horizontal flat plate to air. J. Heat Transfer, 104, (1982) 139-144.

[11]. T. Fujii, H. Imura, , Natural-convection heat transfer from a plate with arbitrary inclination. Int. J. Heat Mass Transfer, 15, (1972)755-767.

[12]. B. R. Rich, Inclined flat plate in free convection. Trans. ASME, 75, (1953) 489-499.

[13]. E. M. Sparrow, R. B. Husar, Longitudinal vortices in natural convection on inclined plates. J. Fluid Mech., 37, (1969) 251-255.

[14]. L. F. A. Azevedo, E. M. Sparrow, Natural convection in open-ended channels. J. Heat Transfer, 107, (1985) 893-901 
[15]. D. Cooper, T. J. Craft, K. Esteifi, H. Iacovides, Experimental investigation of buoyant flows in inclined differentially heated cavities. Int. J. Heat Mass Transfer, 55, (2012) 6321-6339.

[16]. D. Ammour, T.J. Craft and H. Iacovides, "Highly Resolved LES and URANS of Turbulent Buoyancy-Driven Flow within Inclined Differentially-Heated Enclosures", Flow Turbulence Combustion, Volume: 91 Issue: 3 Special Issue: SI, (2013) 669-696

[17]. B.P. Axcell, T.K. Lim, M.A. Cotton, "On the thermal hydraulics of Magnox reactor pressure vessel insulation Part 1: Experimental determination of the thermal performance of multiple plate insulation.", Nuclear Engineering and Design 237, (2007) 694-699 